\title{
Improving gene transfer in human renal carcinoma cells: Utilization of adenovirus vectors containing chimeric type 5 and type 35 fiber proteins
}

\author{
BISHNU ACHARYA ${ }^{1,2}$, SHUJI TERAO ${ }^{1,2}$, TORU SUZUKI ${ }^{1,2}$, MICHIO NAOE $^{3}$, \\ KATSUYUKI HAMADA ${ }^{4}$, HIROYUKI MIZUGUCHI ${ }^{5}$ and AKINOBU GOTOH ${ }^{1,2}$
}

\author{
${ }^{1}$ Laboratory of Cell and Gene Therapy, Institute for Advanced Medical Sciences, Hyogo College of Medicine, \\ Hyogo 663-8501; ${ }^{2}$ Advanced Medical Research Center, Hyogo University of Health Sciences, Hyogo 650-8530; \\ ${ }^{3}$ Department of Urology, Showa University School of Medicine, Tokyo 142-8666; ${ }^{4}$ Department of Obstetrics and Gynecology, \\ Ehime University School of Medicine, Ehime 791-0295; 5 Department of Biochemistry and Molecular Biology, \\ Graduate School of Pharmaceutical Sciences, Osaka University, Osaka 565-0871, Japan
}

Received February 9, 2010; Accepted March 26, 2010

DOI: 10.3892/etm_00000085

\begin{abstract}
The transduction efficacy of adenovirus serotype 5 (Ad5) vector in human renal carcinoma cells is generally low due to the down-regulated expression of Coxsackie and adenovirus receptor (CAR) in target cells. By contrast, the infectivity of adenovirus serotype 35 vectors depends on the binding rate to CD46 receptor, independent of CAR. In this study, we examined whether an adenovirus vector containing chimeric type 5 and type 35 fiber proteins (Ad5/F35) increases transduction efficiency compared to Ad5 vector in human renal carcinoma cells in vitro. The expression of CAR was much lower in the human renal carcinoma cells than in control HEK293 cells. By contrast, the expression of CD46 was similar and perhaps at a higher level in the human renal carcinoma cells than in the HEK293 cells. The transduction efficacy of Ad5/F35 vector was dramatically higher compared to that of Ad5 in human renal carcinoma cells, and was correlated to the expression of CD46. Thus, Ad5/35 vector may be useful for the development of novel gene therapy approaches to renal cell carcinoma.
\end{abstract}

\section{Introduction}

In the US, an estimated 57,760 patients were diagnosed with renal cell carcinoma (RCC) in 2009, of which 12,980 patients succumbed to the disease (1). The prognosis for RCC patients

Correspondence to: Dr Shuji Terao, Laboratory of Cell and Gene Therapy, Institute for Advanced Medical Sciences, Hyogo College of Medicine, 1-1 Mukogawa-cho, Nishinomiya, Hyogo 663-8501, Japan E-mail: terao@hyo-med.ac.jp

Key words: adenovirus vector, transduction efficacy, adenovirus serotype $5 / 35$ vector, renal cell carcinoma with progressive or recurring disease is particularly poor. RCC is relatively resistant to radiotherapy and chemotherapy, and only a minority of patients respond to specific immunotherapy with interleukin-2 and interferon- $\alpha$ (2). Recently, antiangiogenic therapy targeting the angiogenesis pathway was approved for the treatment of advanced stage RCC patients (3-5). Although this treatment appears to be promising, there remains a lack of curative therapy for advanced stage RCC, and currently almost all patients with this condition are incurable. Recent advances in genetic and molecular biology have led to the use of novel approaches, such as gene and virus therapy, for the treatment of RCC. Adenovirus serotype 5 (Ad5) vectors have been traditionally used in pre-clinical experiments and clinical trials (6). Ad5 vectors mediate their attachment and entry into cells using the Coxsackie and adenovirus receptor (CAR) (7). Renal carcinoma cell lines generally express low levels of CAR; as a result Ad5 viruses have a low transduction efficacy in these cells (8).

In order to overcome the low transduction efficacy of Ad5 in cells lacking CAR, several researchers have developed fibermodified Ad vectors with a broader tropism (9). Adenovirus serotype 35 (Ad35) vectors do not interact with CAR, but instead bind to CD46 receptors (also known as MCP-membrane co-factor protein), which are ubiquitously expressed in almost all human cells (10-12). Ad vector containing chimeric type 5 and type 35 fiber proteins (Ad5/F35) is capable of CAR-independent tropism in target cells expressing CD46 on the membrane. Several groups have investigated the utility of Ad5/F35 for the development of transduction efficacy in cells lacking CAR (13-17). In this study, we evaluated the ability of the Ad5/F35 vector to transfer genes to several human renal cell lines, in comparison to the Ad5 vector.

\section{Materials and methods}

Cell lines and cell culture. Established cell lines derived from human renal carcinoma cell lines, namely ACHN and 
Table I. Primers and probes.

\begin{abstract}
CAR
Forward primer

Reverse primer

Probe

CD46
Forward primer
Reverse primer
Probe

GAPDH

Forward primer

Reverse primer

Probe

Caki-1, were obtained from the Cell Resource Center for Biomedical Research Institute of Development, Aging and Cancer, Tohoku University (Sendai, Japan). The RCC4-VHL human renal carcinoma cell line was purchased from the European Collection of Animal Cell Cultures (ECACC; Salisbury, UK). The 786-O human renal carcinoma cell line was purchased from the American Type Culture Collection (ATCC; Manassas, VA, USA). The HEK293 cells were purchased from the RIKEN Bioresource Center (Tsukuba, Japan).
\end{abstract}

\author{
5'-CAGAAGCTACATCGGCAGTAATCA-3' \\ 5'-CTCTGAGGAGTGCGTTCAAAGTC-3' \\ 5'-d FAM-TCCATGTCTCCTTCCAACATGGAAGGA-TAMRA-3'
}

\author{
5'-GGTGTTGCTGCTGTACTCCTTCT-3' \\ 5'-CCAATGAGCTCCATAGCTTCAA-3' \\ 5'-d FAM-CGATGCCTGTGAGGAGCCACCAAC-BHQ-1-3'
}

5'-GAAGGTGAAGGTCGGAGTC-3'

5'-GAAGATGGTGATGGGATTTC-3'

5'-d FAM-CAAGCTTCCCGTTCTCAGCC-BHQ-1-3'
Caki-1 and 786-O cells were maintained in RPMI-1640 medium (Life Technologies, Inc., Gaithersburg, MD, USA) containing $10 \%$ fetal bovine serum (FBS) and antibiotics (50 $\mu \mathrm{g} / \mathrm{ml}$ streptomycin sulfate and $50 \mathrm{IU} / \mathrm{ml}$ penicillin). RCC4-VHL and HEK293 cells were maintained in Dulbecco's modified Eagle's medium (DMEM; Nacalai Tesque, Inc., Kyoto, Japan) containing $10 \% \mathrm{FBS}$, antibiotics $(50 \mu \mathrm{g} /$ $\mathrm{ml}$ streptomycin sulfate and $50 \mathrm{IU} / \mathrm{ml}$ penicillin), $2 \mathrm{mM}$ glutamine and $0.5 \mathrm{~g} / 1$ geneticin. ACHN were maintained in modified Eagle's medium (MEM; Nacalai Tesque, Inc.) containing 10\% FBS, $2 \mathrm{mM}$ glutamine, $10 \mathrm{mM}$ non-essential amino acids and antibiotics $(50 \mu \mathrm{g} / \mathrm{ml}$ streptomycin sulfate and $50 \mathrm{IU} / \mathrm{ml}$ penicillin). All cell lines were maintained at $37^{\circ} \mathrm{C}$ in a humidified incubator with a $5 \% \mathrm{CO}_{2}$ atmosphere and $97 \%$ relative humidity, and were sub-cultured on reaching $80 \%$ confluence using $1 \mathrm{mmol} / 1$ EDTA-0.025\% trypsin for 3-5 min. The cells were transferred 2-3 times/week into fresh growth medium.

In vitro real-time quantitative reverse transcription-PCR assay. Total cellular RNA was isolated from all cell lines using a TaKaRa RNA extraction kit (Parex), and was reverse transcribed using a reverse transcription kit (TaKaRa RNA PCR kit Ver. 3.0) following the manufacturer's protocol. The resulting cDNA was amplified with $\mathrm{CAR}, \mathrm{CD} 46$ and GAPDH sequence-specific primers $\left(40\right.$ cycles, $95^{\circ} \mathrm{C}$ for $15 \mathrm{sec}, 60^{\circ} \mathrm{C}$ for $1 \mathrm{~min}$ ) using TaqMan chemistry in the StepOnePlus RealTime PCR System v2.0 (Applied Biosystems). Table I shows the sequences of the TaqMan probes and primers for CAR, CD46 and GAPDH. All primers/probes were purchased from Biosearch Technologies Japan.
Adenovirus vector preparation. The transduction efficiency of Ad5-LacZ and Ad5/F35-LacZ, chimeric type 5 and type 35 fiber proteins expressing LacZ driven by the cytomegalovirus promoter, were tested (15). Vectors were purified through two rounds of $\mathrm{CsCl}$ gradient ultracentrifugation using standard methods. Serial dilutions of the viruses were used to infect HEK293 cells for a plaque assay. The infectious titer of the purified Ad vectors was determined by triplicate $50 \%$ tissue culture infective dose (TCID50) assays using HEK293 cells, and expressed as plaque-forming units $(\mathrm{pfU}) / \mathrm{ml}$.

Transduction efficacy of adenovirus vectors. In order to determine transduction efficacy in each cell line, $1 \times 10^{5}$ cells were prepared in a 24-well plate and infected with Ad5-LacZ or Ad5/F35-LacZ. After $48 \mathrm{~h}$, the transduction efficacy was assessed by $\beta$-galactosidase ( $\beta$-gal) staining and expressed as blue titer units $(\mathrm{btU}) / \mathrm{ml}$.

Statistical analysis. Statistical significance was determined using ANOVA and Bonferroni correction. A p-value of $<0.05$ was considered statistically significant.

\section{Results}

Relative quantification of CAR and CD46 mRNA expression. Fig. 1 shows the mean relative quantifications of CAR and CD46 mRNA expression as detected in the cell lines. In order to normalize for differences in the quantity of total RNA, GAPDH was selected as the endogenous RNA control. HEK293 cells were selected as the positive control. Relative quantification was calculated with the value obtained from HEK 293 cells set to $100 \%$. Levels of CAR mRNA expression were considerably higher in the RCC4-VHL cell line compared to the Caki-1 (>100-fold), ACHN (>10-fold) and 786-O (8-fold) cell lines. However, the level of CAR mRNA expression in the RCC4-VHL cells was still much lower ( $\sim$.1-fold) than that in the HEK293 cell line. The levels of CD46 mRNA in all the RCC cell lines were relatively high compared to the expression of CAR mRNA. The relative quantification of CD46 mRNA expression in the Caki-1, ACHN and 786-O cell lines was 81.8, 82.1 and 64.6\%, respec- 
A



B

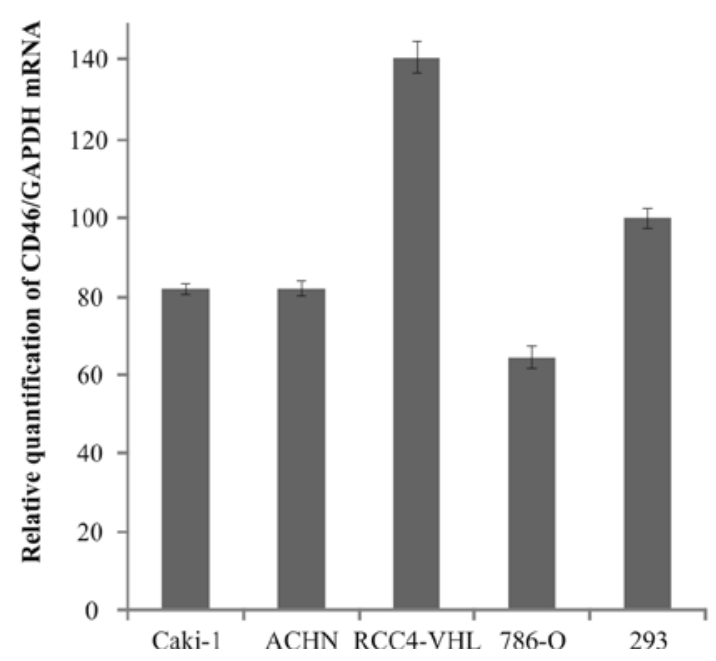

Figure 1. Relative mRNA levels of CAR (A) and CD46 (B) determined by real-time quantitative RT-PCR in human renal carcinoma cell lines. The relative quantification was calculated with the value obtained from HEK293 cells set to 100\%. GAPDH was selected as an endogenous RNA control to normalize differences in the quantity of total RNA. Bars, means \pm SD.

tively. Expression was higher (141.1\%) in the RCC4-VHL cells than in the HEK293 cells.

Transduction efficacy of adenovirus vectors. In order to assess transduction efficacy in all the cell lines, both Ad5-LacZ and Ad5/F35-LacZ were utilized. The transduction efficacy of Ad5-LacZ in Caki-1, ACHN, RCC4-VHL and 786-O cells was $1.3 \times 10^{7}, 3.5 \times 10^{7}, 7.5 \times 10^{7}$ and $5 \times 10^{7} \mathrm{btU} / \mathrm{ml}$, respectively. By contrast, the transduction efficacy of Ad5/F35-LacZ in Caki-1, ACHN, RCC4-VHL and 786-O cells was $1.9 \times 10^{11}$, $1.8 \times 10^{11}, 6.6 \times 10^{11}$ and $6.0 \times 10^{10} \mathrm{btU} / \mathrm{ml}$, respectively (Fig. 2). The transduction efficacy of Ad5/F35-LacZ was significantly higher in all the RCC cell lines compared to that of Ad5-LacZ $(\mathrm{p}<0.01)$.

\section{Discussion}

Gene therapy using Ad5 vector is a promising therapeutic strategy for the treatment of various types of cancer. However, this approach has yet to be developed for use in cases of RCC, possibly due to the low transduction efficiency of the Ad5 vector in these cells. To date, only 12 protocols for the gene therapy of RCC have been applied in a clinical setting, and only one of these used the Ad5 vector. By contrast, more than 990 protocols have been described for other cancers (Gene Therapy Clinical Trials Worldwide, 2009; http://www.wiley. co.uk/genetherapy/clinical/).

In the present study, we attempted to increase the transduction efficiency of the Ad vector in renal carcinoma cells, and thus evaluated a newly developed adenovirus vector, Ad5/F35-LacZ. This vector is capable of CAR-independent tropism in target cells expressing CD46 on the membrane. The results revealed that the transduction efficiency of Ad5/ F35-LacZ in each of the tested renal carcinoma cell lines was significantly higher than that of the Ad5 vector (Fig. 2), and almost paralleled the relative quantifications of CD46 mRNA expression (Fig. 1B).

Previously, we examined the transduction efficiency of Ad5 vector containing the RGD motif in the HI loop of the Ad

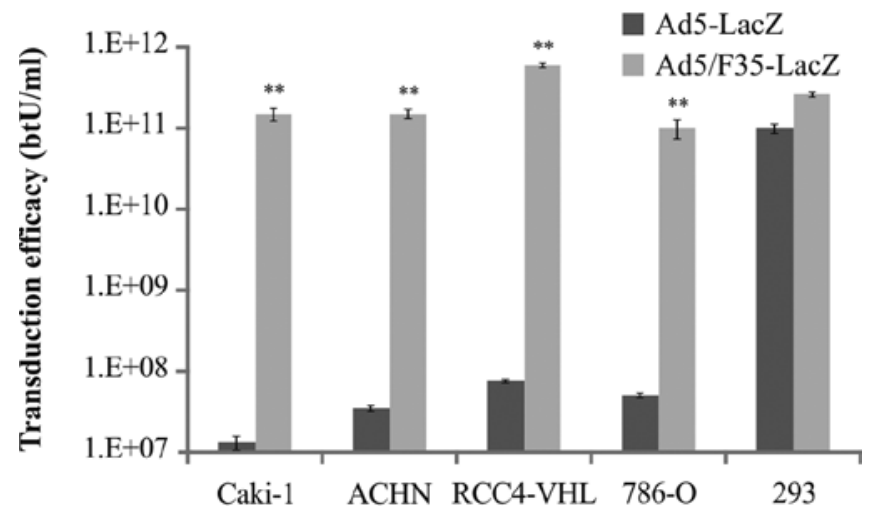

Figure 2. The transduction efficacy of Ad5-LacZ and Ad5/F35-LacZ in human renal carcinoma cell lines. Bars, means \pm SD. ${ }^{* *}$ Significantly different $(\mathrm{p}<0.01)$.

fiber knob (Ad-RGD vector) (18). This vector is capable of CAR-independent tropism in target cells expressing $\alpha v \beta 3$ and/ or $\alpha v \beta 5$ integrin on the membrane (19). Also, this vector was expected to have a high efficacy in renal carcinoma cells due to the overexpression of $\alpha v \beta 3$ integrin in these cells (20). We demonstrated a significant increase in transduction efficacy of 125- to 1,800-fold in human RCC cell lines compared to the transduction efficacy associated with the Ad5 vector (18). The results also showed that the transduction efficacy of Ad5/ F35-LacZ was significantly increased by 8.3-, 10-, 37.5- and 20-fold in the ACHN, Caki-1, RCC4-VHL and 786-O RCC cells, respectively, compared to the Ad-RGD vector. Previous investigators have demonstrated an antitumor effect in various cancer cell lines using an oncolytic Ad5/F35 vector $(21,22)$. The transduction efficacy of the Ad5/F35 vector in the cell lines used in these studies was higher than that of the Ad5 vector. In agreement with these studies, our findings suggest that, in RCC, an oncolytic Ad5/F35 vector containing the Ela gene controlled by a RCC-specific promoter may achieve a greater antitumor effect than gene therapy using a conventional Ad5 vector. 
In this study, we demonstrated a marked increase in the transduction efficacy of renal carcinoma cells using an $\mathrm{Ad}$ vector containing chimeric type 5 and type 35 fiber proteins. It may therefore be preferable to use the Ad vector described in this study to target renal carcinoma cells. The application of our findings may lead to more effective novel gene therapy approaches to renal cell carcinoma.

\section{Acknowledgements}

The authors wish to thank Satoko Kodama for help in the completion of the manuscript.

\section{References}

1. American Cancer Society: Cancer Facts and Figures 2009. American Cancer Society, Atlanta, 2009

2. Coppin C, Porzsolt F, Awa A, Kumpf J, Coldman A and Wilt T: Immunotherapy for advanced renal cell cancer. Cochrane Database Syst Rev 1: CD001425, 2005.

3. Castellano D, Del Muro XG, Pérez-Gracia JL, González-Larriba JL, Abrio MV, Ruiz MA, Pardo A, Guzmán C, Cerezo SD and Grande E: Patient-reported outcomes in a phase III, randomized study of sunitinib versus interferon- $\alpha$ as first-line systemic therapy for patients with metastatic renal cell carcinoma in a European population. Ann Oncol 20: 1803-1812, 2009.

4. Rini BI, Halabi S, Taylor J, Small EJ and Schilsky RL; Cancer and Leukemia Group B: Cancer and Leukemia Group B 90206: a randomized phase III trial of interferon-alpha or interferon-alpha plus anti-vascular endothelial growth factor antibody (bevacizumab) in metastatic renal cell carcinoma. Clin Cancer Res 10 2584-2586, 2004.

5. Yang JC, Haworth L, Sherry RM, Hwu P, Schwartzentruber DJ, Topalian SL, Steinberg SM, Chen HX and Rosenberg SA A randomized trial of bevacizumab, an anti-vascular endothelial growth factor antibody, for metastatic renal cancer. N Engl J Med 349: 427-434, 2003.

6. Hamilton MM, Byrnes GA, Gall JG, Brough DE, King CR and Wei LL: Alternate serotype adenovector provides long-term therapeutic gene expression in the eye. Molecular Vision 14: 2535-2546, 2008.

7. Bergelson JM, Cunningham JA, Droguett G, Kurt-Jones EA, Krithivas A, Hong JS, Horwitz MS, Crowel RL and Finberg RW: Isolation of a common receptor for Coxsackie B viruses and adenoviruses 2 and 5. Science 275: 1320-1323, 1997.

8. Okegawa T, Sayne JR, Nutahara K, Pong RC, Saboorian H, Kabbani W, Higashihara E and Hsieh JT: A histone deacetylase inhibitor enhances adenoviral infection of renal cancer cells. J Urol 177: 1148-1156, 2007.
9. Mizuguchi $H$ and Hayakawa T: Targeted adenovirus vectors. Hum Gene Ther 15: 1034-1044, 2004.

10. Gaggar A, Shayakhmetov DM and Lieber A: CD46 is a cellular receptor for group B adenoviruses. Nat Med 9: 1408-1412, 2003.

11. Segerman A, Atkinson JP, Marttila M, Dennerquist V, Wadell G and Arnberg N: Adenovirus type 11 uses CD46 as a cellular receptor. J Virol 77: 9183-9191, 2003.

12. Marttila M, Persson D, Gustafsson D, Liszewski MK, Atkinson JP, Wadell G and Arnberg N: CD46 is a cellular receptor for all species $B$ adenoviruses except types 3 and 7 . J Virol 79: 14429-14436, 2005.

13. Toyoda E, Doi R, Kami K, Mori T, Ito D, Koizumi M, Kida A, Nagai $K$, Ito $T$, Masui $T$, Wada $M$, Tagawa $M$ and Uemoto $S$ : Adenovirus vectors with chimeric type 5 and 35 fiber proteins exhibit enhanced transfection of human pancreatic cancer cells. Int J Oncol 33: 1141-1147, 2008.

14. Yu L, Shimozato O, Li Q, Kawamura K, Ma G, Namba M, Ogawa T, Kaiho I and Tagawa M: Adenovirus type 5 substituted with type 11 or 35 fiber structure increases its infectivity to human cells enabling dual gene transfer in CD46-dependent and independent manners. Anticancer Res 27: 2311-2316, 2007.

15. Mizuguchi $\mathrm{H}$ and Hayakawa $\mathrm{T}$ : Adenovirus vectors containing chimeric type 5 and type 35 fiber proteins exhibit altered and expanded tropism and increase the size limit of foreign genes. Gene 20: 69-77, 2002.

16. Ni S, Gaggar A, Di Paolo N, Li ZY, Liu Y, Strauss R, Sova P, Morihara J, Feng Q, Kiviat N, Touré P, Sow PS and Lieber A: Evaluation of adenovirus vectors containing serotype 35 fibers for tumor targeting. Cancer Gene Ther 13: 1072-1081, 2006.

17. Yu L, Takenobu H, Shimozato O, Kawamura K, Nimura Y, Seki N, Uzawa K, Tanzawa H, Shimada H, Ochiai $T$ and Tagawa M: Increased infectivity of adenovirus type 5 bearing type 11 or type 35 fibers to human esophageal and oral carcinoma cells. Oncol Rep 14: 831-835, 2005.

18. Terao S, Acharya B, Suzuki T, Aoi T, Naoe M, Hamada K, Mizuguchi $\mathrm{H}$ and Gotoh $\mathrm{A}$ : Improved gene transfer into renal carcinoma cells using adenovirus vector containing RGD motif. Anticancer Res 29: 2997-3002, 2009.

19. Koizumi N, Mizuguchi H, Kondoh M, Fujii M, Nakanishi T, Utoguchi $\mathrm{N}$ and Watanabe $\mathrm{Y}$ : Efficient gene transfer into differentiated human trophoblast cells with adenovirus vector containing RGD motif in the fiber protein. Biol Pharm Bull 29: 1297-1299, 2006.

20. Wechsel HW, Petri E, Feil G, Nelde HJ, Bichler KH and Loesr W: Renal cell carcinoma: immunohistological investigation of expression of the integrin alpha $v$ beta 3 . Anticancer Res 19: 1529-1532, 1999.

21. Chen L, Chen D, Gong M, Na M, Li L, Wu H, Jiang L, Qian Y, Fang $\mathrm{G}$ and Xue X: Concomitant use of Ad5/35 chimeric oncolytic adenovirus with TRAIL gene and taxol produces synergistic cytotoxicity in gastric cancer cells. Cancer Lett 284: 141-148, 2009.

22. Toivonen R, Suominen E, Grenman R and Savontaus M: Retargeting improves the efficacy of a telomerase-dependent oncolytic adenovirus for head and neck cancer. Oncol Rep 21 165-171, 2009. 